\title{
Dexmedetomidine versus propofol-opioid for sedation in transcatheter aortic valve implantation patients: a retrospective analysis of periprocedural gas exchange and hemodynamic support
}

\section{Dexmédétomidine versus propofol-opioïde pour la sédation des patients recevant une implantation transcathéter de valve aortique : analyse rétrospective de l'échange gazeux et du soutien hémodynamique en période périprocédurale}

\author{
N. Patrick Mayr, MD • Gunther Wiesner, MD • Pieter van der Starre, MD, PhD • \\ Alexander Hapfelmeier, PhD - Gertrud Goppel, MD • Albert Markus Kasel, MD • \\ Christian Hengstenberg, MD - Oliver Husser, MD, PhD · Heribert Schunkert, MD • \\ Peter Tassani-Prell, MD
}

Received: 14 August 2017/Revised: 8 January 2018/Accepted: 8 January 2018/Published online: 20 February 2018

(C) Canadian Anesthesiologists' Society 2018

\begin{abstract}
Purpose Different sedation regimens have been described for use during transfemoral transcatheter aortic valve implantation (tf-TAVI) for treatment in patients with severe
\end{abstract}

N. P. Mayr, MD $(\varangle) \cdot$ G. Wiesner, MD · P. Tassani-Prell, MD Institut für Anästhesiologie, Deutsches Herzzentrum München des Freistaates Bayern, Technische Universität München, Lazarettstr. 36, 80636 Munich, Germany

e-mail: patrick.mayr@tum.de

P. van der Starre, $\mathrm{MD}, \mathrm{PhD}$

Department of Anesthesiology and Perioperative Medicine, Stanford University School of Medicine, Stanford, CA, USA

\section{A. Hapfelmeier, $\mathrm{PhD}$}

Institut für Medizinische Statistik und Epidemiologie, Klinikum Rechts der Isar, Technische Universität München, Munich, Germany

G. Goppel, MD

Klinik für Herz- und Gefäßchirurgie, Deutsches Herzzentrum München des Freistaates Bayern, Technische Universität München, Munich, Germany

A. M. Kasel, MD - C. Hengstenberg, MD .

O. Husser, MD, PhD - H. Schunkert, MD

Klinik für Herz- und Kreislauferkrankungen, Deutsches Herzzentrum München des Freistaates Bayern, Technische

Universität München, Munich, Germany

C. Hengstenberg, MD · H. Schunkert, MD

DZHK, Partner Site Munich Heart Alliance, Munich, Germany aortic stenosis. The purpose of this study was to compare dexmedetomidine (DEX) with a combination of propofol-opioid (PO) with respect to periprocedural gas exchange and hemodynamic support.

Methods Data from a cohort of patients sedated with either DEX or PO for tf-TAVI were retrospectively analyzed from a prospectively maintained TAVI registry. Operative risk was determined from comorbidities and risk scores. Periprocedural partial pressure of carbon dioxide $\left(\mathrm{P}_{a} \mathrm{CO}_{2}\right)$ was chosen as the primary endpoint. Other differences in gas exchange, need for catecholamine therapy, the frequency of conversion to general anesthesia, and need for sedative "rescue therapy" (in DEX patients) were secondary endpoints. Inverse probability of treatment weighting (IPTW) was used for analysis to minimize any selection bias.

Results Of the 297 patients (140 PO, 157 DEX) included, the median [interquartile range] periprocedural $\mathrm{P}_{a} \mathrm{CO}_{2}$ values of DEX patients were significantly lower than in $P O$ patients $(40$ [36-45] $\mathrm{mmHg}$ vs 44 [40-49] $\mathrm{mmHg}$, respectively; median difference $-4 \mathrm{mmHg} ; 95 \%$ confidence interval, -5 to $-3 \mathrm{mmHg} ; P<0.001)$. Hypercapnia $\left(\mathrm{P}_{a} \mathrm{CO}_{2}>45 \mathrm{mmHg}\right)$ was significantly less frequent in DEX patients compared with the PO group (25\% vs $42 \%$, respectively; $P=0.005)$. Vasopressor support was more frequent in the PO group compared with DEX (68\% vs $25 \%$, respectively; $P<0.001)$. Conversion to general anesthesia was not different between groups (9\%, 
PO vs 3\%, DEX; $P=0.051)$. Additional sedatives/opioids were required in 25 (16\%) of the DEX patients.

Conclusions In sedated TAVI patients, DEX was associated with lower $\mathrm{P}_{a} \mathrm{CO}_{2}$ values and reduced requirements for vasopressor support, making it a promising alternative to PO for sedation during TAVI.

Trial registration $w w w$.ClinicalTrials.gov (NCT01390675). Registered 11 July 2011.

\section{Résumé}

Objectif L'utilisation de divers protocoles de sédation a été proposée au cours de l'implantation transcathéter de valve aortique par voie fémorale (tf-TAVI) pour le traitement des patients présentant une sténose aortique sévère. L'objectif de cette étude était de comparer l'impact de la dexmédétomidine (DEX) à celui d'une association propofol-opioüde (PO) sur l'échange gazeux et le soutien hémodynamique en période périprocédurale.

Méthodes Les données issues d'une cohorte de patients ayant reçu une sédation par DEX ou PO pour une tf-TAVI ont été analysées de manière rétrospective à partir d'un registre TAVI tenu de façon prospective. Le risque opératoire était déterminé à partir des comorbidités et des scores de risque. La pression partielle de dioxyde de carbone $\left(\mathrm{P}_{a} \mathrm{CO}_{2}\right)$ en période périprocédurale a été choisie comme critère d'évaluation principal. Les autres différences concernant les échanges gazeux, le besoin de traitement par catécholamines, la fréquence des conversions en anesthésie générale et le besoin d'un " traitement de secours » sédatif (pour les patients DEX) ont été les critères d'évaluation secondaires. La pondération $d u$ traitement selon la probabilité inverse (IPTW) a servi à minimiser des biais de sélection dans l'analyse.

Résultats Parmi les 297 patients (140 PO, 157 DEX) inclus, les valeurs médianes [écart interquartile] de la $\mathrm{P}_{a} \mathrm{CO}_{2}$ en période périprocédurale ont été significativement inférieures à celles des patients $P O$ (respectivement, 40 [36 à 45] mmHg contre 44 [40 à 49] $\mathrm{mmHg}$; différence entre médianes $-4 \mathrm{mmHg}$; intervalle de confiance à $95 \%$ : $\quad-5$ à $-3 \mathrm{mmHg} ; \quad P<0,001)$. L'hypercapnie $\quad\left(\mathrm{P}_{a} \mathrm{CO}_{2}>45 \mathrm{mmHg}\right) \quad a \quad$ été significativement moins fréquente chez les patients DEX comparativement au groupe PO (respectivement, $25 \%$ contre $42 \%$; $P<0,005)$. Le soutien par agents vasopresseurs a été plus fréquent dans le groupe PO par rapport au groupe DEX (respectivement, $68 \%$ contre $25 \%$; $P<0,001)$. Il n'y a pas eu de différence entre les deux groupes pour la conversion en anesthésie générale (PO $9 \%$ contre DEX $3 \% ; P<0,051)$. Des sédatifs/ opiö̈des supplémentaires ont été nécessaires chez 25 (16\%) des patients du groupe DEX.
Conclusions Chez les patients recevant une sédation pour TAVI, DEX a été associée à des valeurs de $\mathrm{P}_{a} \mathrm{CO}_{2}$ inférieures et à un moindre besoin de soutien en agents vasopresseurs; DEX constitue une alternative prometteuse à l'association PO pour la sédation au cours d'une TAVI. Enregistrement de l'essai clinique $w w w$.ClinicalTrials. gov (NCT01390675). Enregistré le 11 juillet 2011.

With more than 350,000 procedures performed worldwide to date, ${ }^{1}$ transcatheter aortic valve implantation (TAVI) has become an established therapy for elderly and other highrisk patients with severe aortic stenosis. In North America and Europe, more than 9,000 and 17,000 patients, respectively, are expected to receive this therapy annually. ${ }^{2}$ Of the different available access routes, transfemoral TAVI (tf-TAVI) is considered to be the least invasive and is, therefore, the most frequently chosen approach for valve implantation. Although general anesthesia was the preferred anesthetic technique in the early days of TAVI, it has largely being replaced with sedation techniques. ${ }^{3}$ Thus far, neither of the reported anesthetic techniques has shown clinical superiority, ${ }^{4,5}$ though few prospective randomized data are available. Despite this, there is continued increasing interest in performing tf-TAVI under sedation, ${ }^{6}$ especially as the clinical results of newer, even less invasive devices are promising. ${ }^{7}$

Various sedation techniques have been previously described, ${ }^{3}$ though there is no consensus regarding the optimal pharmacologic strategy during tf-TAVI. Favourable pharmacologic properties such as rapid onset of unconsciousness and a rapid awakening have made propofol—often combined with benzodiazepines or opioids-the preferred choice for sedation during interventional procedures. ${ }^{8}$ Nevertheless, adverse effects such as hypotension, ${ }^{9,10}$ as well as hypoxemia and hypercapnia, potentially causing an increase of the sometimes already elevated pulmonary artery pressures, ${ }^{9,11}$ have been described. ${ }^{12}$

Available in the US since 1999, dexmedetomidine (DEX), a selective $\alpha_{2}$-adrenoceptor agonist with sedative effects, ${ }^{13}$ was approved by European authorities for clinical use in 2011. Due to its sympatholytic properties, DEX can cause dose-related decreases in heart rate, blood pressure, and myocardial oxygen consumption. ${ }^{13,14}$ In addition, DEX may extend analgesic effects (i.e., opioid sparing) especially in combination with locoregional anesthesia techniques. ${ }^{15}$ Patients receiving DEX are described as sleeping comfortably, while at the same time being easily rousable. Due to the lack of respiratory depression and 
consequent adverse changes in gas exchange, ${ }^{13}$ DEX is considered an alternative to propofol for sedation of highrisk patients.

In this analysis, we hypothesized that periprocedural arterial carbon dioxide $\left(\mathrm{CO}_{2}\right)$ partial pressure $\left(\mathrm{P}_{\mathrm{a}} \mathrm{CO}_{2}\right)$ values would be higher in patients sedated with a propofolopioid (PO) combination compared with DEX sedated patients. Furthermore, differences in other blood gas parameters, the need for catecholamine therapy, the frequency of conversion to general anesthesia, and the need for a sedative "rescue therapy" in the DEX group were also investigated as secondary endpoints.

\section{Methods}

\section{Patient population}

Data were retrospectively analyzed from our prospectively maintained Anesthesia for catheter aortic Valve ImplantATiOn Registry (AVIATOR) TAVI registry (www.ClinicalTrials.gov; NCT01390675). All patients provided written informed consent and the inclusion of data into the study registry received ethics committee approval (Medical Faculty, Technische Universität München 06/20/2011). The tf-TAVI procedures were all performed at the Deutsches Herzzentrum München, a university hospital specialized in cardiovascular disease, where an interdisciplinary heart team of cardiac surgeons and interventional cardiologists determined the indication for TAVI and the method of implantation. Technical aspects of the procedure have been previously described in detail. ${ }^{5,16}$ Although sedation has been used since 2011 in our TAVI program, DEX was first available in June 2013. In this study, we used data from all consecutive patients from 12 June 2013 to 26 April 2016 undergoing tf-TAVI with either PO or DEX sedation.

\section{Sedation strategies}

Moderate sedation ("conscious sedation")—as defined by the American Society of Anesthesiologists ${ }^{17}$ —was chosen as the targeted depth of sedation and was clinically assessed by the attending anesthesiologist. Moderate sedation was defined as purposeful response to verbal or tactile stimulation with adequate spontaneous ventilation maintained without airway intervention and usually with preserved cardiovascular function. Both sedation techniques were used by only three selected cardiac anesthesiologists experienced in TAVI sedation. The choice of sedation technique was at the discretion of the attending anesthesiologist. All patients received oral premedication with $3.75 \mathrm{mg}$ of midazolam $30 \mathrm{~min}$ before arrival in the operating room. All patients received $8 \mathrm{~L}$ of oxygen per minute via facemask after insertion of the radial artery catheter. In addition to standard perioperative monitoring in accordance with standard guidelines ${ }^{18}$ that included capnography, arterial and central venous pressures were also invasively monitored. The central venous catheter (internal jugular vein) was placed using ultrasound guidance under local anesthesia. In both groups, the groin was infiltrated with $20 \mathrm{~mL}$ of lidocaine $1 \%$ (each side) at the beginning of the procedure by the interventionalist.

In the PO group, the sedation was started after placement of the radial artery catheter. A single additional dose of midazolam $\left(0.01-0.03 \mathrm{mg} \cdot \mathrm{kg}^{-1} i v\right)$ was given for anxious patients at the discretion of the anesthesiologist. A propofol infusion was started in a range of $1-2 \mathrm{mg} \cdot \mathrm{kg}^{-1} \cdot \mathrm{hr}^{-1}$ and titrated to achieve the moderate ("conscious") sedation level as defined above. ${ }^{17}$ Either remifentanil or fentanyl was used for opioid supplementation with the remifentanil dose being 0.01 $0.04 \mu \mathrm{g} \cdot \mathrm{kg}^{-1} \cdot \mathrm{min}^{-1}$ and fentanyl given as a single bolus of $1-2 \mu \mathrm{g} \cdot \mathrm{kg}^{-1}$ at the beginning of sedation.

In the DEX group, the infusion was started at a rate of $0.7 \mu \mathrm{g} \cdot \mathrm{kg}^{-1} \cdot \mathrm{hr}^{-1}$ immediately after placement of the radial artery catheter. After $20 \mathrm{~min}$, the dose was adjusted within the recommended range of $0.2-1.4 \mu \mathrm{g} \cdot \mathrm{kg}^{-1} \cdot \mathrm{hr}^{-1}$ to achieve the desired depth of sedation. For the placement of the central venous catheter under local anesthesia, a single dose of midazolam (0.01-0.03 $\left.\mathrm{mg} \cdot \mathrm{kg}^{-1} i v\right)$ and ketamine (0.1-0.4 $\left.\mathrm{mg} \cdot \mathrm{kg}^{-1} i v\right)$ was administered.

\section{Endpoints assessed}

Arterial blood gas measurements were performed at baseline (breathing room air and before any sedation) immediately after placement of the radial arterial catheter and repeated three minutes after heparin administration (i.e., periprocedural). As hypercapnia could influence pulmonary vascular resistance and right ventricular function, ${ }^{19-21}$ periprocedural $\mathrm{P}_{\mathrm{a}} \mathrm{CO}_{2}$ (as continuous variable) was chosen a priori as a clinically important primary endpoint. The number of patients with a periprocedural $\mathrm{P}_{\mathrm{a}} \mathrm{CO}_{2}>45 \mathrm{mmHg}$ (defining hypercapnia) was also secondarily evaluated. Other secondary endpoints included periprocedural hypotension (mean arterial pressure $<65 \mathrm{mmHg}$ ), ${ }^{22}$ which, whenever it occurred, was treated with a single $5 \mu \mathrm{g} i v$ norepinephrine bolus. A continuous norepinephrine infusion was started in situations where more than five boluses were needed. ${ }^{5}$ Epinephrine was given for ino- and chronotropic support in case of bradycardia $\left(<40\right.$ beats $\left.\cdot \mathrm{min}^{-1}\right)$ in conjunction with hypotension (mean arterial pressure $<65 \mathrm{mmHg}$ ) and in case of vasopressor-refractory hypotension. 
Conversion to general anesthesia was defined as the need for a periprocedural endotracheal intubation, independent of the underlying cause, but with the exclusion of procedure-related cases. Procedure-related conversion was defined by clinical situations where a conversion to general anesthesia was necessary to resolve a procedural adverse event (and not to a sedation-related event); these included major vascular injury (according to
Valve Academic Research Consortium-2), ${ }^{23}$ pericardial tamponade, coronary obstruction, and valve embolization. Patients requiring a procedure-related conversion to general anesthesia were excluded from the final sedation analysis (Fig. 1).

The need for sedative "rescue therapy" was assessed in patients receiving DEX sedation and was defined as sedation insufficient during the procedure (assessed by

Fig. 1 Patient flow diagram. tf-

TAVI $=$ transfemoral

transcatheter aortic valve

implantation

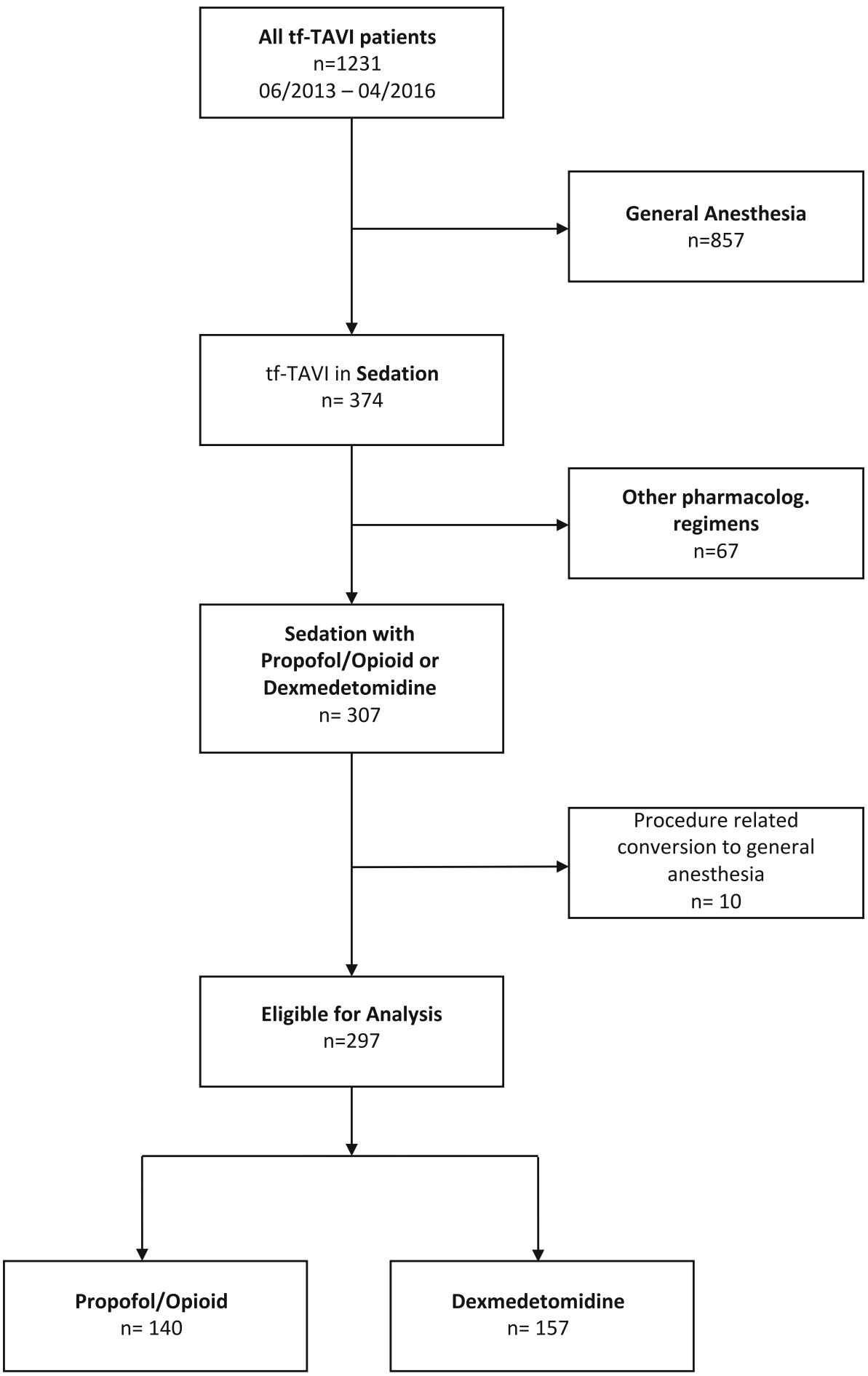


the attending anesthesiologist) that required bolus administrations of propofol and/or opioids. Typically, propofol was given to deepen sedation in cases of patient discomfort; however, the interventionalist was also advised to repeat the local anesthesia with $10 \mathrm{~mL}$ of lidocaine $1 \%$ on the affected side. In case of continued pain, opioid supplementation was started. "Successful sedative rescue therapy" was defined as a situation in which a successful additional sedation was achieved without the need to convert to general anesthesia.

Other adverse events that were assessed included the need for synchronized cardioversion or defibrillation (for a tachyarrhythmia and concurrent hypotension) as well as the use of (CPR), which was defined as the use of chest compressions along with pharmacologic resuscitation. Emergency extracorporeal circulation (ECC) was defined as any unplanned use of periprocedural ECC.

\section{Statistical analysis}

The sample size was determined by convenience according to the availability of DEX at our institution starting from June 2013. Nevertheless, based on an expected median (interquartile range [IQR]) $\mathrm{P}_{\mathrm{a}} \mathrm{CO}_{2}$ of 47 [41-57] $\mathrm{mmHg}$ in the PO group, a sample size of 140 in each group was expected to have $80 \%$ power to detect even a weak effect size of 0.336 (i.e., mean difference in $\mathrm{P}_{\mathrm{a}} \mathrm{CO}_{2}$ levels between groups divided by the common standard deviation) using a two-group $t$ test with a 5\% two-sided significance level (nQuery Advisor 7.0).

The distribution of continuous and categorical variables is presented as median [IQR] or absolute and relative frequencies, respectively. Following recent advances in statistical methodology on the estimation of causal treatment effects in observational studies, inverse probability of treatment weighting (IPTW) ${ }^{24}$ using propensity scores was used for the comparison of patient cohorts with control for potential selection bias induced by confounders such as sex, body mass index, New York Heart Association (NYHA) class, insulin-dependent diabetes mellitus, peripheral arterial vascular disease, left ventricular ejection fraction, renal impairment, pulmonary hypertension in accordance with EuroScore II, and chronic lung disease-as defined by the Society of Thoracic Surgeons (STS) score ${ }^{25}$-in this observational, nonrandomized setting. The stabilized weights used in IPTW were computed from propensity scores that were assessed through a random forest ${ }^{26}$ prediction model. The latter is capable of modelling the possibly complex relations among the aforementioned confounders more accurately than logistic regression. Weighting was finally implemented by weighted quantile regression ${ }^{27}$ to obtain estimates and for hypothesis testing on differences in median values and interquartile ranges of continuous variables. Similarly, weighted binary logistic regression models and weighted multinomial log-linear regression models ${ }^{28}$ were used for the analysis of categorical variables. All statistical tests were performed on exploratory, two-sided $5 \%$ significance levels. R 3.3.1 ${ }^{29}$ was used to conduct the analyses.

\section{Results}

Two hundred ninety-seven patients (PO, $n=140$; DEX, $n=$ 157) had sedation for TAVI performed in accordance with the described protocols. Table 1 shows the unweighted preprocedural patient characteristics in both groups and those after IPTW. The success of weighting can be seen in preprocedural variables such as the number of female patients, age, EuroSCORE II, STS score, NYHA class, insulin-dependent diabetes mellitus, renal impairment, moderate or severe lung disease, and pulmonary arterial pressure.

The $\mathrm{P}_{\mathrm{a}} \mathrm{O}_{2}$ and $\mathrm{P}_{\mathrm{a}} \mathrm{CO}_{2}$ values were comparable between the two patient groups prior to sedation (Table 2). Nevertheless, periprocedural $\mathrm{P}_{\mathrm{a}} \mathrm{CO}_{2}$ values were significantly lower in the DEX than in the PO group (40 [36-45] mmHg vs 44 [40-49] $\mathrm{mmHg}$, respectively; median difference, $-4 \mathrm{mmHg} ; 95 \%$ confidence interval, -5 to -3 mmHg; $P<0.001)$. Likewise, the $\mathrm{P}_{\mathrm{a}} \mathrm{O}_{2}$ values were also higher in the DEX group $(P=0.02)$. Figure 2 shows the unweighted density plots of $\mathrm{PaCO}_{2}$ and $\mathrm{P}_{\mathrm{a}} \mathrm{O}_{2}$ at baseline and periprocedurally. The procedural curve shows a rightward shift to higher $\mathrm{PaCO}_{2}$ values in the $\mathrm{PO}$ group (left bottom) and a similar shift for $\mathrm{P}_{\mathrm{a}} \mathrm{O}_{2}$ values in the DEX group (right bottom). Hypercapnia $\left(\mathrm{P}_{\mathrm{a}} \mathrm{CO}_{2}>45 \mathrm{mmHg}\right)$ was significantly less frequent in DEX patients compared with the PO group (IPTW: $25 \%$ vs $42 \%$, respectively; $P=$ $0.005)$.

Clinically indicated pharmacologic hemodynamic support (particularly especially norepinephrine) was required significantly more often in the PO group $(P<$ 0.001). Significantly more DEX patients received epinephrine for inotropic and chronotropic support $(P=$ 0.024). Nevertheless, the total amount of epinephrine administered was higher in the PO group $(P<0.001)$ (Table 2).

In total, conversion to general anesthesia was needed in 12 patients in the PO group (IPTW: 9\%) and five patients in the DEX group (IPTW: $3 \%)(P=0.051)$. Respiratory compromise was the most common reason for conversion in PO patients $(n=6)$ whereas agitation was the most common reason in the DEX group $(n=3)$. Short-term bagmask ventilation was needed in two PO patients. Temporary bradypnea was recorded in four patients in each group (PO 3\%, DEX 3\%). A jaw thrust maneuver in 
Table 1 Baseline patient characteristics

\begin{tabular}{|c|c|c|c|c|}
\hline & \multicolumn{2}{|c|}{ Unweighted population } & \multicolumn{2}{|l|}{ IPTW } \\
\hline & $\mathrm{PO}$ & DEX & $\mathrm{PO}$ & DEX \\
\hline$n$ & $140(47 \%)$ & $157(53 \%)$ & & \\
\hline Female patients & $61(44 \%)$ & $73(46 \%)$ & $45 \%$ & $46 \%$ \\
\hline Age (yr) & $82[78-86]$ & $81[77-85]$ & $81[78-86]$ & $81[78-86]$ \\
\hline BMI $\left(\mathrm{kg} \cdot \mathrm{m}^{-2}\right)$ & $25.9[23.5-28.7]$ & $25.8[23.4-29.4]$ & $26.2[23.5-29.0]$ & $25.8[23.4-29.4]$ \\
\hline EuroSCORE II (\%) & $4.0[2.3-6.7]$ & $3.4[2.1-5.4]$ & $3.7[2.1-6.2]$ & $3.7[2.1-5.7]$ \\
\hline STS mortality (\%) & $4.1[2.8-7.3]$ & $3.5[2.4-5.2]$ & $3.8[2.7-6.7]$ & $3.7[2.5-5.3]$ \\
\hline $\operatorname{LVEF}(\%)$ & $55[41-60]$ & $55[50-57]$ & $55[45-60]$ & $55[48-56]$ \\
\hline $\operatorname{AVA}\left(\mathrm{cm}^{2}\right)$ & $0.8[0.6-0.9]$ & $0.7[0.6-0.9]$ & $0.8[0.60-0.9]$ & $0.7[0.6-0.8]$ \\
\hline Max. pressure gradient (mmHg) & $67[49-82]$ & $70[55-84]$ & $68[50-84]$ & $70[54-82]$ \\
\hline Mean pressure gradient $(\mathrm{mmHg})$ & $41[32-52]$ & $44[33-52]$ & $42[33-52]$ & $44[30-52]$ \\
\hline NYHA III/IV & $108(77 \%)$ & $106(68 \%)$ & $74 \%$ & $72 \%$ \\
\hline History of stroke/TIA & $13(9 \%)$ & $21(13 \%)$ & $9 \%$ & $14 \%$ \\
\hline History of myocardial infarction & $17(12 \%)$ & $17(11 \%)$ & $12 \%$ & $11 \%$ \\
\hline Insulin dependent diabetes mellitus & $12(9 \%)$ & $5(3 \%)$ & $7 \%$ & $4 \%$ \\
\hline \multicolumn{5}{|l|}{ Renal impairment* } \\
\hline Normal & $7(5 \%)$ & $10(6 \%)$ & $5 \%$ & $6 \%$ \\
\hline Moderate & $65(46 \%)$ & $82(52 \%)$ & $50 \%$ & $51 \%$ \\
\hline Severe & $68(49 \%)$ & $65(41 \%)$ & $45 \%$ & $43 \%$ \\
\hline Dialysis & $1(1 \%)$ & 0 & $1 \%$ & $0 \%$ \\
\hline Moderate or severe lung disease according to STS Score ${ }^{28}$ & $15(11 \%)$ & $18(10 \%)$ & $10 \%$ & $11 \%$ \\
\hline \multicolumn{5}{|l|}{ Pulmonary arterial pressure (systolic) } \\
\hline$<30 \mathrm{mmHg}$ & $59(42 \%)$ & $78(59 \%)$ & $44 \%$ & $47 \%$ \\
\hline $31-55 \mathrm{mmHg}$ & $49(35 \%)$ & $59(38 \%)$ & $37 \%$ & $37 \%$ \\
\hline$>55 \mathrm{mmHg}$ & $32(23 \%)$ & $20(13 \%)$ & $18 \%$ & $15 \%$ \\
\hline
\end{tabular}

The distribution of data is presented as median [interquartile range] for continuous variables and by absolute and relative frequencies for categorical variables

$\mathrm{AVA}=$ aortic valve area; $\mathrm{BMI}=$ body mass index DEX $=$ dexmedetomidine; IPTW $=$ inverse probability of treatment weighting; LVEF $=$ left ventricular ejection fraction; NYHA = New York Heart Association; PO = propofol/opioid; STS = Society of Thoracic Surgeons; TIA = transient ischemic attack

$*$ Renal function definitions: normal $=$ creatinine clearance $>85 \mathrm{~mL} \cdot \mathrm{min}^{-1} ;$ moderate $=$ creatinine clearance $50-85 \mathrm{~mL} \cdot \mathrm{min}^{-1} ; \mathrm{severe}^{2} \mathrm{creatinine}$ clearance $<50 \mathrm{~mL} \cdot \mathrm{min}^{-1}$

conjunction with a nasopharyngeal airway was used in one PO $(1 \%)$ and three DEX $(2 \%)$ patients.

In terms of sedation efficacy, additional successful analgesic and sedatives (i.e., "rescue medication") were required in 25 patients (16\%) receiving DEX. In 17 patients $(11 \%)$ only propofol (0.5 [0.3-0.7] $\left.\mathrm{mg} \cdot \mathrm{kg}^{-1}\right)$ was administered to deepen sedation. In four others $(2.5 \%)$, a combination of opioids (fentanyl 0.8 [0.8-1.2] $\mu \mathrm{g} \cdot \mathrm{kg}^{-1}$ ) and propofol (0.6 [0.4-2.3] $\left.\mathrm{mg} \cdot \mathrm{kg}^{-1}\right)$ was given. Four patients $(2.5 \%)$ received only opioids (fentanyl, $n=1$, total dose: $1.4 \mu \mathrm{g} \cdot \mathrm{kg}^{-1}$; remifentanil, $n=3$, total dose: 1.3 $\mu \mathrm{g} \cdot \mathrm{kg}^{-1}, 1.6 \mu \mathrm{g} \cdot \mathrm{kg}^{-1}$ and $4.1 \mu \mathrm{g} \cdot \mathrm{kg}^{-1}$ ) for pain relief.

Periprocedural complications including CPR and ECC, as well as synchronized cardioversion or defibrillation, are also summarized in Table 2. The use of CPR was needed in one patient in each group, while cardioversion or defibrillation was applied in three patients of the PO group (2\%) only.

\section{Discussion}

The most important elements of successful sedation are an adequate depth of sedation-as determined by the requirements of the patient and the interventionalist-as well as respiratory and hemodynamic stability. The results of this study show lower values of $\mathrm{P}_{\mathrm{a}} \mathrm{CO}_{2}$ at a defined point during the procedure, less need for vasopressor support, and a tendency for less conversion to general anesthesia in patients sedated with DEX compared with PO for tf-TAVI. 
Table 2 Periprocedural data

\begin{tabular}{|c|c|c|c|c|c|c|}
\hline & \multicolumn{3}{|c|}{ Unweighted population } & \multicolumn{3}{|l|}{ IPTW } \\
\hline & $\mathrm{PO}$ & DEX & $P$ value & $\mathrm{PO}$ & DEX & $P$ value \\
\hline$n$ & 140 & 157 & & & & \\
\hline \multicolumn{7}{|l|}{ Times } \\
\hline Anesthesia time (min) & $\begin{array}{l}125[110- \\
150]\end{array}$ & $110[90-130]$ & 0.009 & $\begin{array}{l}125[110- \\
155]\end{array}$ & $\begin{array}{c}110[90- \\
130]\end{array}$ & 0.01 \\
\hline Induction time (min) & $30[25-40]$ & $15[15-25]$ & 0.009 & $30[25-40]$ & $15[15-25]$ & 0.004 \\
\hline Procedure time (min) & $60[45-70]$ & $55[45-70]$ & 0.38 & $60[45-70]$ & $55[45-70]$ & 0.37 \\
\hline Length ICU stay (days) & $1[1-2]$ & $1[1-1]$ & 0.99 & $1[1-2]$ & $1[1-1]$ & 0.99 \\
\hline Length hospital stay (days) & $4[4-7]$ & $4[4-7]$ & 0.99 & $5[4-7]$ & $5[4-7]$ & 0.99 \\
\hline \multicolumn{7}{|l|}{ Routine pharmacologic therapy } \\
\hline Infusion $\mathrm{RiAc}\left(\mathrm{mL} \cdot \mathrm{kg}^{-1}\right)$ & 14 [11-19] & $13[10-17]$ & 0.11 & 14 [11-19] & $13[10-17]$ & 0.07 \\
\hline $\begin{array}{l}\text { Dose dexmedetomidine before balloon valvuloplasty } \\
\qquad\left(\mu \mathrm{kg}^{-1} \mathrm{~h}^{-1}\right)\end{array}$ & & $0.7[0.6-0.9]$ & & & & \\
\hline $\begin{array}{l}\text { Dose dexmedetomidine after balloon valvuloplasty } \\
\qquad\left(\mu \mathrm{g} \mathrm{kg}^{-1} \mathrm{~h}^{-1}\right)\end{array}$ & & $0.7[0.5-0.8]$ & & & & \\
\hline Total dose dexmedetomidine $\left(\mu \mathrm{g} \mathrm{kg}^{-1}\right)$ & & $0.85[0.67-1.08]$ & & & & \\
\hline Total dose propofol $\left(\mathrm{mg} \cdot \mathrm{kg}^{-1}\right)$ & 2.4 [1.7-3.3] & $0.5[0.3-0.7]^{*}$ & & & & \\
\hline Remifentanil $(n)$ & $81(57 \%)$ & $3(2 \%) *$ & & & & \\
\hline Total dosage remifentanil $\left(\mu \mathrm{g} \mathrm{kg}^{-1}\right)$ & $2.4[1.6-4.3]$ & $\begin{array}{l}1.6[1.3-4.1]^{*} \text { (rescue } \\
\text { therapy) }\end{array}$ & & & & \\
\hline Fentanyl $(n)$ & $64(45 \%)$ & $5(3 \%) *$ & & & & \\
\hline Total dose fentanyl $\left(\mu \mathrm{g} \cdot \mathrm{kg}^{-1}\right)$ & $1.3[1.0-1.5]$ & $\begin{array}{l}0.1[0.8-1.3]^{*} \text { (rescue } \\
\text { therapy) }\end{array}$ & & & & \\
\hline Catecholaminergic therapy $(n)$ & $98(69 \%)$ & $54(34 \%)$ & $<0.001$ & $68 \%$ & $35 \%$ & $<0.001$ \\
\hline Norepinephrine therapy $(n)$ & $98(69 \%)$ & $39(25 \%)$ & $<0.001$ & $68 \%$ & $25 \%$ & $<0.001$ \\
\hline Epinephrine therapy $(n)$ & $7(5 \%)$ & $19(12 \%)$ & 0.02 & $4 \%$ & $12 \%$ & 0.02 \\
\hline Total dose norepinephrine $\left(\mu \mathrm{g} \cdot \mathrm{kg}^{-1}\right)$ & $1.9[1.2-3.2]$ & $1.6[0.9-2.0]$ & 0.33 & $2.0[1.2-3.3]$ & $1.6[0.9-2.0]$ & 0.20 \\
\hline Total dose epinephrine $\left(\mu \mathrm{g} \cdot \mathrm{kg}^{-1}\right)$ & $2.2[0.5-2.6]$ & $0.1[0-0.3]$ & $<0.001$ & $2.2[0.5-2.5]$ & $0.1[0.0-0.3]$ & $<0.001$ \\
\hline \multicolumn{7}{|l|}{ Periprocedural complications } \\
\hline Conversion to general anesthesia $(n)$ & $12(8 \%)$ & $5(3 \%)$ & 0.06 & $9 \%$ & $3 \%$ & 0.05 \\
\hline Synchronized cardioversion or defibrillation $(n)$ & $3(2 \%)$ & 0 & 0.10 & $2 \%$ & 0 & 0.99 \\
\hline Cardiopulmonary resuscitation $(n)$ & $1(0.7 \%)$ & $1(0.6 \%)$ & 0.72 & $0.8 \%$ & $0.5 \%$ & 0.76 \\
\hline Emergency ECC $(n)$ & 0 & 0 & - & & & \\
\hline Death OR $(n)$ & 0 & 0 & - & & & \\
\hline \multicolumn{7}{|l|}{ Respiratory parameters } \\
\hline \multicolumn{7}{|l|}{ Baseline room air } \\
\hline $\mathrm{S}_{\mathrm{a}} \mathrm{O}_{2}(\mathrm{mmHg})$ & $96[94-96]$ & $96[94-96]$ & 0.99 & 96 [94-97] & 96 [94-97] & 0.99 \\
\hline $\mathrm{P}_{\mathrm{a}} \mathrm{O}_{2}(\mathrm{mmHg})$ & 77 [69-84] & 78 [70-85] & 0.69 & 77 [69-85] & 77 [70-85] & 0.86 \\
\hline $\mathrm{P}_{\mathrm{a}} \mathrm{CO}_{2}(\mathrm{mmHg})$ & 36 [33-39] & 36 [33-39] & 0.52 & 36 [33-39] & 36 [33-39] & 0.45 \\
\hline $\mathrm{pH}$ & $\begin{array}{l}7.46[7.43- \\
7.48]\end{array}$ & $7.45[7.43-7.47]$ & 0.54 & $\begin{array}{l}7.46[7.43- \\
7.48]\end{array}$ & $\begin{array}{l}7.45[7.43- \\
\quad 7.47]\end{array}$ & 0.39 \\
\hline \multicolumn{7}{|l|}{ Periprocedural } \\
\hline $\mathrm{S}_{\mathrm{a}} \mathrm{O}_{2}(\mathrm{mmHg})$ & 99 [99-99] & 99 [99-99] & 0.09 & 99 [99-99] & 99 [99-99] & 0.07 \\
\hline $\mathrm{P}_{\mathrm{a}} \mathrm{O}_{2}(\mathrm{mmHg})$ & $\begin{array}{l}169[132- \\
226]\end{array}$ & $201[150-242]$ & 0.02 & $\begin{array}{l}174[135- \\
228]\end{array}$ & $\begin{array}{l}201[146- \\
238]\end{array}$ & 0.02 \\
\hline $\mathrm{P}_{\mathrm{a}} \mathrm{CO}_{2}(\mathrm{mmHg})$ & 44 [40-49] & 40 [37-45] & $<0.001$ & 44 [40-49] & 40 [36-45] & $<0.001$ \\
\hline $\mathrm{pH}$ & $\begin{array}{l}7.38[7.35- \\
7.40]\end{array}$ & $7.40[7.37-7.44]$ & 0.06 & $\begin{array}{l}7.38[7.35- \\
\quad 7.40]\end{array}$ & $\begin{array}{l}7.40[7.37- \\
\quad 7.44]\end{array}$ & 0.04 \\
\hline
\end{tabular}


Table 2 continued

\begin{tabular}{|c|c|c|c|c|c|c|}
\hline & \multicolumn{3}{|c|}{ Unweighted population } & \multicolumn{3}{|c|}{ IPTW } \\
\hline & $\mathrm{PO}$ & DEX & $P$ value & $\mathrm{PO}$ & DEX & $P$ value \\
\hline Hypercapnia $\left(\mathrm{P}_{\mathrm{a}} \mathrm{CO}_{2}>45 \mathrm{mmHg}\right)(n)$ & $45(32 \%)$ & $37(23 \%)$ & 0.004 & $42 \%$ & $25 \%$ & 0.005 \\
\hline
\end{tabular}

The distribution of data is presented by median [interquartile range] for continuous variables and by absolute and relative frequencies for categorical variables. *Rescue therapy

Anesthesia time $=$ the time from patient arrival in the OR until transfer to the ICU; DEX = dexmedetomidine; ECC = extracorporeal circulation; ICU = intensive care unit; IPTW = inverse probability of treatment weighting; OR = operating room; $\mathrm{PaCO}_{2}=$ partial pressure carbon dioxide; $\mathrm{PO}=$ propofol/opioid; $\mathrm{RiAc}=$ Ringer's acetate infusion; $\mathrm{SaO}_{2}=$ oxygen saturation

Preservation of respiratory function has been described for DEX. It specifically targets central $\alpha_{2}$-adrenergic receptors $^{13}$ and is not associated with the same degree of respiratory depression as propofol. Propofol causes global central nervous system depression by interacting with gamma-aminobutyric acid-A and N-methyl-D-aspartate receptors. ${ }^{30}$ With propofol, respiratory compromise with a reduction of the airway cross-sectional area has been observed, the highest level of obstruction occurring at the base of the tongue. ${ }^{31}$ This is accompanied by hypoventilation, especially in combination with opioids, causing hypercapnia- a finding replicated in the PO group of this study. Hypercapnia may lead to an increase of pulmonary vascular resistance and worsen right ventricular function in these often hemodynamically compromised TAVI patients. ${ }^{19-21}$ In the currently described cohort, conversion to general anesthesia due to respiratory compromise was not observed in DEX patients, which is consistent with results from previous trials. Significant sedation benefits to DEX have also been seen in other settings. For example, patients randomized to a DEX/ ketamine combination for endoscopic retrograde cholangiopancreatography experienced significantly fewer sedation-related adverse events, including desaturation and hypotension, compared with those in the propofol/opioid group, ${ }^{32}$ and similar results have been reported in other settings. ${ }^{33,34}$

Sedation-related hemodynamic instability in TAVI procedures is a difficult endpoint to determine, as procedural steps can directly cause hemodynamic instability. Aortic regurgitation due to balloon valvuloplasty, implantation of balloon-expandable valves under rapid ventricular pacing, and temporary obstruction of the left ventricular outflow tract during implantation of self-expanding valves either directly cause hypotension or may precipitate subsequent hemodynamic instability. As a result, we utilized the total need of vasopressors required during a procedure as a surrogate parameter for hemodynamic stability. During TAVI, the use of sedatives with minimal hemodynamic effects is preferred and traditional agents may be harmful. Propofol causes hypotension because of relaxation of vascular smooth muscle cells and inhibition of sympathetic vasoconstrictor activity. ${ }^{35}$ This may explain the higher need for vasopressor support observed in the PO group. DEX is also associated with hypotension, ${ }^{36}$ but mainly when bolus administration is applied, which was not the case in the study group. Overall, we used low doses of DEX, which might have contributed to the low requirement for vasopressors. Nevertheless, DEX is known to reduce sympathetic nervous system activity ${ }^{37}$ and suppress catecholamine release, ${ }^{38}$ and we found more patients requiring low doses of epinephrine for ino- and chronotropic support.

Conversion to general anesthesia occurred numerically more often in the PO group, though this was not statistically significant, with respiratory compromise being the most common cause. In contrast, pain and agitation were the primary reasons for conversion in the DEX group though DEX itself is rarely known to cause agitation during procedural sedation. ${ }^{39}$

In tf-TAVI, the majority of procedural steps are performed in the vascular system. The insertion of the large-gauge femoral access sheath is the most painful step in this procedure. Adequate local anesthesia and a sufficient level of sedation are crucial during this period. In centres performing tf-TAVI without anesthetic support, ${ }^{40}$ local anesthesia, sometimes supplemented with a minimal dose of sedatives/analgesics, is often the primary and only source of analgesia.

Additional sedatives/opioids as "rescue medication" were required in $25(16 \%)$ of the patients in the DEX group. Inadequate local anesthesia and pain led to eight (5\%) cases requiring additional therapy. Most of the patients receiving "rescue medication" (11\%) required additional application of propofol to deepen their sedation to enhance comfort and improve the implant conditions. Sedation with DEX has been shown to reduce cold and ischemic pain, while propofol sedation was associated with a reduction of ischemia-induced pain; however, the analgesic effect of both substances is considered to be weak. In our patient cohort, DEX sedation was sufficient 


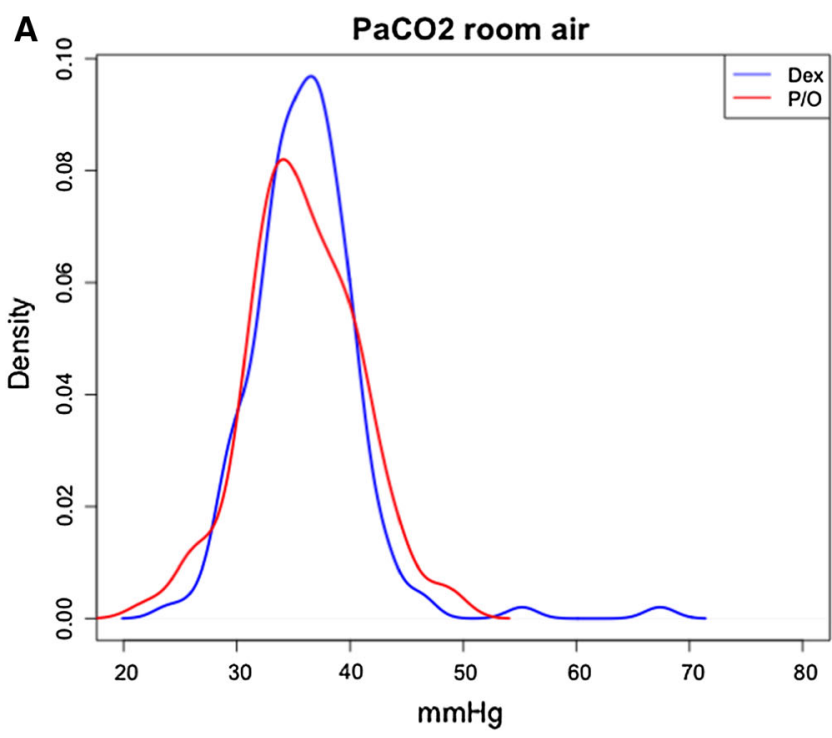

B

$\mathrm{PaO2}$ room air

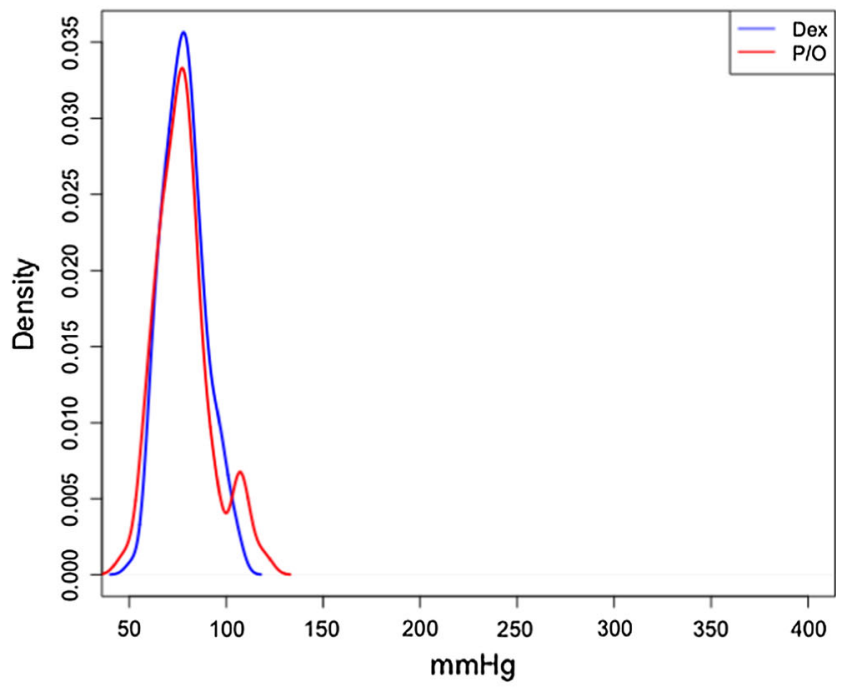

PaCO2 periprocedural
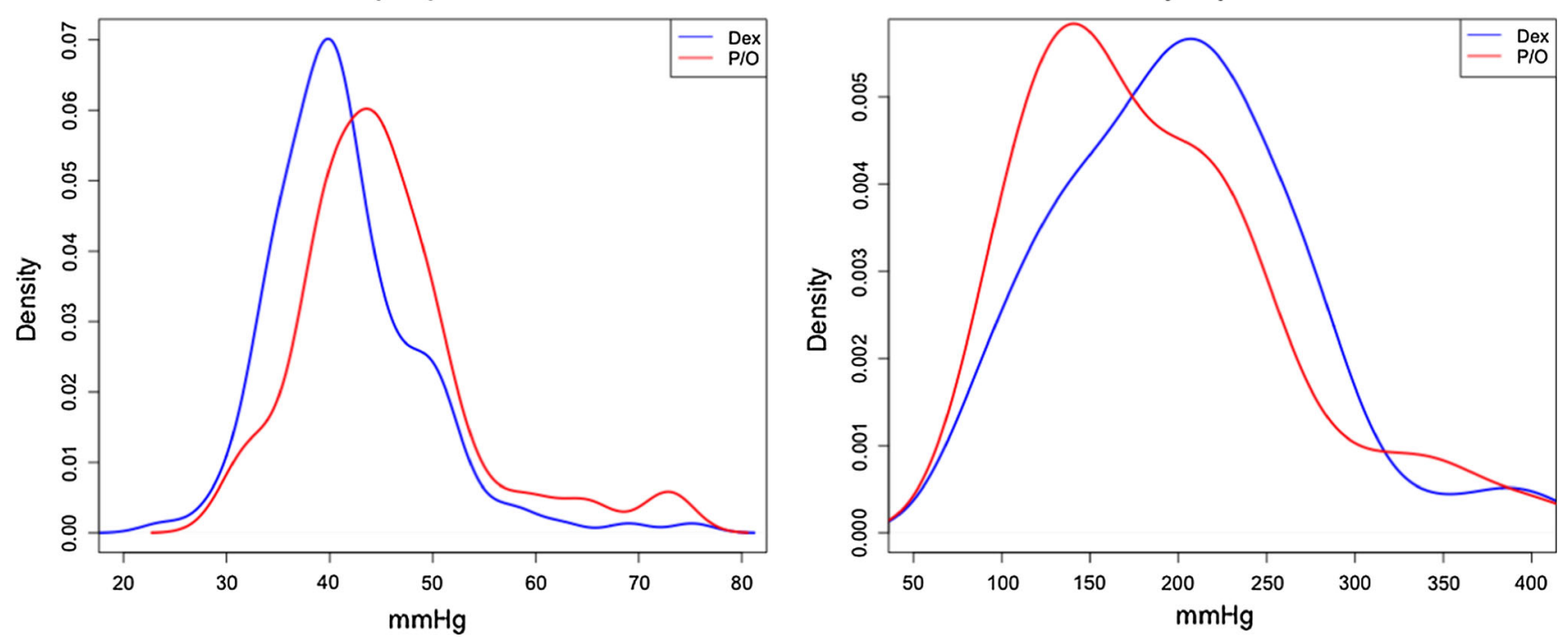

Fig. 2 A) Density plot of absolute partial pressure of carbon dioxide $\left(\mathrm{P}_{\mathrm{a}} \mathrm{CO}_{2}\right)$ and $\left.\mathrm{B}\right)$ partial pressure of oxygen $\left(\mathrm{P}_{\mathrm{a}} \mathrm{O}_{2}\right)$ values at baseline (breathing room air with no sedation) and periprocedural

for $84 \%$ of the patients. High inter-individual variability, especially in pharmacokinetics, has been described for DEX. $^{15,41}$ This might be an additional explanation for the need of sedative "rescue therapy". Furthermore, in contrast to propofol with its rapid onset, ${ }^{42}$ the time to the onset and the peak sedative effect of DEX have been described as five and 15 min respectively, ${ }^{43}$ resulting in some lack of titrability. No "sedative rescue therapy" was necessary in the PO group as the flow rates of the continuous infusions of propofol and remifentanil can easily be titrated to effect.

\section{Limitations}

As these results were from was a single centre where only three anesthesiologists performed the procedures, the generalizability of the data is uncertain. Confirmation of the results would need study in a future randomized controlled multi-centre trial. Most of all the application of a sophisticated statistical model (IPTW) for the comparison of the patient cohorts was used to prevent bias in the estimation of treatment effects and patient selection. The IPTW and propensity score matching remove systematic differences between treated and untreated subjects to a comparable degree. ${ }^{44}$ In contrast to propensity matching alone, this statistical method allows us to present data from all patients.

Data on gas exchange relied only on two arterial blood gas sampling times. Nevertheless, as the periprocedural blood gas was drawn during the insertion of the large-bore sheath, where sufficient sedation is needed, it was done at 
the crucial time point. Qualitative end-expiratory $\mathrm{CO}_{2}$ measures were done throughout the procedure. But this measurement is influenced by a number of clinical factors (e.g., by a variable fraction of ambient air). Therefore, these data were not included in our analysis.

\section{Conclusions}

In patients undergoing tf-TAVI under sedation, DEX was associated with a significantly lower rate of hypercapnia, reduced requirements for norepinephrine hemodynamic support, and a tendency to a lower rate of unplanned intubation compared with patients receiving PO. Preserved gas exchange and hemodynamic stability are cornerstones of safe TAVI sedation. Dexmedetomidine may be an attractive alternative to $\mathrm{PO}$ for sedation of tf-TAVI patients; however, prospective randomized data are needed to determine the optimal strategy.

Acknowledgement The authors thank their study nurse, Doris Kienmoser, for her valuable support in conducting this study.

Conflict of interest All authors declare no conflict of interest.

Editorial responsibility This submission was handled by Dr. Hilary P. Grocott, Editor-in-Chief, Canadian Journal of Anesthesia.

Author contributions N. Patrick Mayr contributed substantially to all aspects of this manuscript, including conception and design; acquisition, analysis, and interpretation of data; and drafting the article. Gunther Wiesner and Alexander Hapfelmeier contributed substantially to all aspects of this manuscript, including conception and design; analysis and interpretation of data; and drafting the article. Pieter van der Starre contributed substantially to designing and drafting the article. Gertrud Goppel and Albert Markus Kasel revised the article. Christian Hengstenberg and Oliver Husser contributed substantially to interpretation of data and drafting the article. Heribert Schunkert contributed substantially to drafting the article. Peter Tassani-Prell contributed substantially to conception and design, interpretation of data, and drafting the article.

\section{References}

1. Barbanti M, Webb JG, Gilard M, Capodanno D, Tamburino C. Transcatheter aortic valve implantation in 2017: state of the art. EuroIntervention 2017; 13(AA): AA11-21.

2. Osnabrugge RL, Mylotte D, Head SJ, et al. Aortic stenosis in the elderly: disease prevalence and number of candidates for transcatheter aortic valve replacement: a meta-analysis and modeling study. J Am Coll Cardiol 2013; 62: 1002-12.

3. Mayr NP, Michel J, Bleiziffer S, Tassani P, Martin K. Sedation or general anesthesia for transcatheter aortic valve implantation (TAVI). J Thorac Dis 2015; 7: 1518-26.

4. Maas EH, Pieters BM, Van de Velde M, Rex S. General or local anesthesia for TAVI? A systematic review of the literature and meta-analysis. Curr Pharmacol Des 2016; 22: 1868-78.
5. Mayr NP, Hapfelmeier A, Martin K, et al. Comparison of sedation and general anaesthesia for transcatheter aortic valve implantation on cerebral oxygen saturation and neurocognitive outcome. Br J Anaesth 2016; 116: 90-9.

6. Oguri A, Yamamoto M, Mouillet $G$, et al. Clinical outcomes and safety of transfemoral aortic valve implantation under general versus local anesthesia: subanalysis of the French Aortic National CoreValve and Edwards 2 registry. Circ Cardiovasc Interv 2014; 7: 602-10.

7. Husser $O$, Pellegrini $C$, Kessler $T$, et al. Outcomes after transcatheter aortic valve replacement using a novel balloonexpandable transcatheter heart valve: a single-center experience. JACC Cardiovasc Interv 2015; 8: 1809-16.

8. Lavi S, Jolly SS, Bainbridge D, Manji F, Randhawa V, Lavi $R$. Sedation, analgesia, and anaesthesia variability in laboratorybased cardiac procedures: an international survey. Can J Cardiol 2014; 30: 627-33.

9. Boer F, Ros P, Bovill JG, van Brummelen P, van der Krogt J. Effect of propofol on peripheral vascular resistance during cardiopulmonary bypass. Br J Anaesth 1990; 65: 184-9.

10. Hammaren E, Hynynen M. Haemodynamic effects of propofol infusion for sedation after coronary artery surgery. $\mathrm{Br} \mathrm{J}$ Anaesth 1995; 75: 47-50.

11. Heuss LT, Froehlich F, Beglinger C. Nonanesthesiologistadministered propofol sedation: from the exception to standard practice. Sedation and monitoring trends over 20 years. Endoscopy 2012; 44: 504-11.

12. Weaver CS, Terrell KM, Bassett R, et al. ED procedural sedation of elderly patients: is it safe? Am J Emerg Med 2011; 29: 541-4.

13. Kallio A, Scheinin $M$, Koulu $M$, et al. Effects of dexmedetomidine, a selective alpha 2-adrenoceptor agonist, on hemodynamic control mechanisms. Clin Pharmacol Ther 1989; 46: $33-42$.

14. Chen $S$, Hua F, Lu J, et al. Effect of dexmedetomidine on myocardial ischemia-reperfusion injury. Int $\mathrm{J}$ Clin Exp Med 2015; 8: 21166-72.

15. Weerink MA, Struys MM, Hannivoort LN, Barends CR, Absalom $A R$, Colin $P$. Clinical pharmacokinetics and pharmacodynamics of dexmedetomidine. Clin Pharmacokinet 2017; 56: 893-913.

16. Rodes-Cabau J. Transcatheter aortic valve implantation: current and future approaches. Nat Rev Cardiol 2012; 9: 15-29.

17. American Society of Anesthesiologists ASo. Position on Monitored Anesthesia Care. Standards, Guidelines, Statements and Other Documents. Available from URL: http://www.asahq. org/quality-and-practice-management/standards-guidelines-andrelated-resources/position-on-monitored-anesthesia-care (accessed January 2018).

18. Dobson G, Chong M, Chow L, et al. Guidelines to the practice of anesthesia - revised edition 2018. Can J Anesth 2018; 65: 76-104.

19. Minai OA, Yared JP, Kaw R, Subramaniam K, Hill NS. Perioperative risk and management in patients with pulmonary hypertension. Chest 2013; 144: 329-40.

20. Lumb $A B$, Slinger $P$. Hypoxic pulmonary vasoconstriction: physiology and anesthetic implications. Anesthesiology 2015; 122: 932-46.

21. Noble WH, Kay JC, Fisher JA. The effect of PCO2 on hypoxic pulmonary vasoconstriction. Can Anaesth Soc J 1981; 28: 42230.

22. Rivers E, Nguyen B, Havstad $S$, et al. Early goal-directed therapy in the treatment of severe sepsis and septic shock. N Engl J Med 2001; 345: 1368-77.

23. Kappetein AP, Head SJ, Genereux P, et al. Updated standardized endpoint definitions for transcatheter aortic valve implantation: the Valve Academic Research Consortium-2 consensus document. J Thorac Cardiovasc Surg 2013; 145: 6-23. 
24. Austin PC, Stuart EA. Moving towards best practice when using inverse probability of treatment weighting (IPTW) using the propensity score to estimate causal treatment effects in observational studies. Stat Med 2015; 34: 3661-79.

25. The Society of Thoracic Surgeons. STS Adult Cardiac Surgery Risk Calculator - Data Version 2.81; 2016. Available from URL: http://riskcalc.sts.org/stswebriskcalc/ - /calculate (accessed January 2018).

26. Strobl C, Boulesteix AL, Zeileis A, Hothorn T. Bias in random forest variable importance measures: illustrations, sources and a solution. BMC Bioinformatics 2007; 8: 25.

27. Koenker R. Quantreg: Quantile Regression. R package version 5.26. 2016. Available from URL: https://cran.r-project.org/ package=quantreg (accessed January 2018).

28. Venables WN, Ripley BD. Modern Applied Statistics with S. 4th ed. NY: Springer-Verlag; 2002 .

29. $R$ Core Team. The $\mathrm{R}$ Project for Statistical Computing. Foundation for Statistical Computing,Vienna, Austria; 2016. Available from URL: https://www.r-project.org/ (accessed January 2018).

30. Kotani Y, Shimazawa M, Yoshimura S, Iwama $T$, Hara $H$. The experimental and clinical pharmacology of propofol, an anesthetic agent with neuroprotective properties. CNS Neurosci Ther 2008; 14: 95-106.

31. Ehsan Z, Mahmoud M, Shott SR, Amin RS, Ishman SL. The effects of anesthesia and opioids on the upper airway: a systematic review. Laryngoscope 2016; 126: 270-84.

32. Goyal R, Hasnain S, Mittal S, Shreevastava S. A randomized, controlled trial to compare the efficacy and safety profile of a dexmedetomidine-ketamine combination with a propofolfentanyl combination for ERCP. Gastrointest Endosc 2016; 83: 928-33.

33. Goettel N, Bharadwaj S, Venkatraghavan L, Mehta J, Bernstein $M$, Manninen $P H$. Dexmedetomidine vs propofol-remifentanil conscious sedation for awake craniotomy: a prospective randomized controlled trial. Br J Anaesth 2016; 116: 811-21.
34. Lee JM, Lee SK, Lee SJ, Hwang WS, Jang SW, Park EY. Comparison of remifentanil with dexmedetomidine for monitored anaesthesia care in elderly patients during vertebroplasty and kyphoplasty. J Int Med Res 2016; 44: 307-16.

35. Robinson BJ, Ebert TJ, O'Brien TJ, Colinco MD, Muzi M. Mechanisms whereby propofol mediates peripheral vasodilation in humans. Sympathoinhibition or direct vascular relaxation? Anesthesiology 1997; 86: 64-72.

36. Khalil M, Al-Agaty A, Asaad $O$, et al. A comparative study between propofol and dexmedetomidine as sedative agents during performing transcatheter aortic valve implantation. J Clin Anesth 2016; 32: 242-7.

37. Zhang $X$, Wang $R, L u J$, et al. Effects of different doses of dexmedetomidine on heart rate and blood pressure in intensive care unit patients. Exp Ther Med 2016; 11: 360-6.

38. Singh $S$, Singh A. Dexmedetomidine induced catecholamine suppression in pheochromocytoma. J Nat Sci Biol Med 2014; 5: 182-3.

39. Banik S, Rath GP, Huygen FJ. Dexmedetomidine infusion may cause agitation during procedural sedation. Pain Pract 2016; 16: E89.

40. Greif $M$, Lange $P$, Nabauer $M$, et al. Transcutaneous aortic valve replacement with the Edwards SAPIEN XT and Medtronic CoreValve prosthesis under fluoroscopic guidance and local anaesthesia only. Heart 2014; 100: 691-5.

41. Kurnik D, Muszkat M, Sofowora $G G$, et al. Ethnic and genetic determinants of cardiovascular response to the selective alpha 2adrenoceptor agonist dexmedetomidine. Hypertension 2008; 51: 406-11.

42. Rathmell JP, Rosow C. Stoelting's Pharmacology and Physiology in Anesthetic Practice, 5th ed: Wolters Kluwer Health; 2015.

43. Kaur M, Singh PM. Current role of dexmedetomidine in clinical anesthesia and intensive care. Anesth Essays Res 2011; 5: 128-33.

44. Austin PC. An introduction to propensity score methods for reducing the effects of confounding in observational studies. Multivariate Behav Res 2011; 46: 399-424. 